\title{
Libros y folletos de la Internacional Comunista en América Latina. Algunos apuntes para su historia
}

\author{
Books and brochures of the Communist International in Latin America. \\ Some notes for your story
}

Manuel Loyola T.*

Resumen: En el terreno de la historia cultural del libro y la edición, ofrecemos aquí un conjunto de antecedentes relacionados con el quehacer editorial comunista en América Latina, en particular en el período de vigencia de la Internacional Comunista. Interrogamos sobre las iniciativas y resultados obtenidos por la mencionada gestión editorial mediante el acopio de diversos datos provenientes tanto de fuentes secundarias como primarias impresas. El objetivo de este trabajo es establecer una base informativa que permita avanzar en el estudio pormenorizado de la función editorial comunista en nuestros países, apuntando a arrojar luz sobre la diversidad de aspectos que esto implicó en áreas de la propaganda, la formación política, la organización empresarial, etc., así como obtener una visión acerca de los resultados y la función del impreso en la evolución de la cultura comunista local.

Palabras clave: Internacional Comunista, comunismo latinoamericano, empresas editoriales, lecturas políticas, cultura política

\begin{abstract}
In the field of the cultural history of the book and the edition, we offer here a set of antecedents related to the work of communist publishing in Latin America, particularly in the period of action of the Communist International. We question the initiatives and results obtained by the aforementioned editorial management by collecting various data from both secondary and printed primary sources. The objective of this work is to establish an information base that allows progress in the detailed study of the communist editorial function in our countries, aiming to shed light on the diversity of aspects that this implied in areas of propaganda, political formation, organization business, etc., as well as obtaining a vision about the results and the role of the print in the evolution of the local communist culture.
\end{abstract}

Keywords: Communist International, Latin American communism, publishing companies, political readings, political culture

Recibido: 2 mayo 2019 Aceptado: 23 agosto 2019

\footnotetext{
*Chileno, Doctor en Estudios Americanos, académico de la Universidad Finis Terrae, mloyola@uft.cl
} 
Esta propuesta se propone balizar las múltiples acciones que, de modo directo e indirecto, llevó a cabo la Internacional Comunista en asuntos de producción y difusión de monografías (libros y folletos) en o para América Latina ${ }^{1}$. No por simple retórica académica, no estará demás señalar que el tema indicado aún tiene bastante de inédito, más si el mismo, como aquí pretendemos, busca ser estudiado desde una perspectiva transnacional abarcando a varios lugares de América Latina2.

A la par con especificar la amplia gama de títulos, autores y materias de las monografías de auspicio cominterniano -trabajo que, por su propia naturaleza no podrá quedar completo en esta ocasión- pondremos especial atención a las estructuras y mecanismos organizacionales que sustentaron la producción y distribución. De este modo, junto a la multiplicidad factual del objeto libro, nos importa sobremanera acercarnos a los medios de gestión, mecanismos de apoyo, redes y entornos que facilitaron y/o canalizaron la propuesta lectoral de la Internacional con relación a América Latina. En breve, la historia del libro y la edición comunista que ahora abordaremos, implica tanto su cuantificación e identificación, como la idea del rol político público que estos productos debían desempeñar, sin olvidar, de paso, los medios y articulaciones operativas que buscaron su vigencia y utilidad. En tercer lugar, en un momento venidero, la gama documental y su sistematización, deberá dar paso al estudio de las características morfosintácticas, así como al recorte de los variados usos y funciones lingüísticas que la producción bibliográfica que nos ocupa puso en juego -estructuras y desplazamientos retóricos, en general- a fin de explicar y disuadir a sus lectores reales, potenciales o imaginados.

En síntesis, a base de un conjunto de antecedentes recogidos tanto en la literatura especializada como en fuentes primarias de reciente publicación, buscamos aquí fijar las primeras señas del área temática de la producción y distribución de los productos impresos -libros y folletos- que llevó a cabo la Internacional Comunista en o para América Latina durante la primera mitad del siglo XX. Por su carácter inicial, nuestra labor necesariamente adquiere un carácter provisional y fragmentario a la espera de otros aportes y desarrollos. A pesar de ello, procuraremos asentar las características que adquirió el hecho editorial mencionado.

\section{II}

Los acontecimientos revolucionarios rusos de 1917 no sólo abrieron paso, en 1922, a la creación de la URSS, sino también, como manifestación explícita del impacto y

\footnotetext{
${ }^{1}$ Aclaración. Entenderemos por folleto toda monografía y/o compilación monográfica cuya extensión no supere los 50 folios, no importando su formato y encuadernación. En este sentido, libro propiamente tal, será todo impreso monográfico o compilatorio superior a las 50 páginas impresas.

2 En la especificidad temática, así como en el alcance supranacional, ha incidido, de modo determinante, la encomiable y alentadora labor que Ricardo Melgar Bao ha cumplido en torno a estos ámbitos de la edición cominterniana: la hemerografía sobre revistas y prensa periódica provista por numerosas organizaciones partidarias y sectoriales vinculadas al comunismo regional de la primera mitad del siglo XX.
} 
proyecciones que tales hechos tuvieron en el socialismo mundial de comienzos del siglo XX, abonarían a la articulación, en marzo de 1919, de la Internacional Comunista (IC, Tercera Internacional, Comintern), concebido como único y auténtico órgano rector de las luchas por el cambio del capitalismo a nivel planetario.

Al margen de numerosas memorias y recuerdos de antiguos militantes, crónicas periodísticas, novelas y otros tantos libelos generalmente críticos o abiertamente recriminatorios, sólo desde hace pocas décadas la trayectoria de la Comintern ha comenzado a tener un tratamiento historiográfico más adecuado y consistente. En cierta forma, la propia liquidación de la experiencia de Octubre favorecería este tipo de indagatorias impulsándose el acercamiento y cruce entre nuevas interrogantes e inquietudes disciplinarias y el acceso más amplio a la documentación y archivos de los desaparecidos regímenes socialistas ${ }^{3}$.

Entre la diversidad de aspectos que conformaron la presencia de la Internacional Comunista en América Latina, los relacionados con los libros y folletos, implica un excelente lugar para ofrecer nuevas miradas acerca del rol y gravitación que la dicha Internacional tuvo en la cultura organizacional, política y militante que, directa o indirectamente, caracterizó a segmentos considerables de la izquierda regional durante el siglo XX. De esta manera, si bien la perspectiva editorial puede servir de complemento para los avatares historiográficos sobre la Comintern, estimamos que los datos e interpretaciones que podemos reunir sobre la labor editorial cominterniana, pueden ir más allá de tal complemento, aportando antecedentes y matices que bien pueden enriquecer el conocimiento histórico sobre lo que fue la experiencia de la IC en estas latitudes. En este sentido, la expresión de complemento perfectamente devendría en suplemento, fortaleciéndose la connotación de ausencia o carencia de factores hasta el momento conocidos, los mismos que vendrían a "completar" -aunque no a terminar- una determinada problemática historiográfica. En fin, estamos pues delante de una "necesidad" heurística y contingente que, unida a otras, daría mejor comprensión de lo que buscamos desentrañar4.

Hablar de la experiencia editorial impulsada por la Comintern nos permite, en primer lugar, insertar este quehacer en una línea temporal de largo aliento derivada de los fundamentos mismos del Iluminismo y la forja del mundo moderno, con su profunda confianza en la razón y la racionalidad humanas a fin de transformar la naturaleza y la

\footnotetext{
${ }^{3}$ Para un panorama sobre el estado del arte respecto de los estudios del comunismo en Europa y otros lugares, consultar: Bruno Groppo, "Historiens et historiographie du communisme en Italie", Revista Izquierdas, 15, abril 2013, pp. 170-192, en https://bit.ly/2KvmOIt ; Lazar Jeifets y Víctor Jeifets, América Latina en la Internacional Comunista. 1919-1943. Diccionario Biográfico, Ariadna Ediciones, Santiago, 2015, en https://bit.ly/2WY4Gs2

4 Por ejemplo, aún con muy poca o fragmentaria información en nuestro medio, dispositivos tales como las emisiones radiales para España y América Latina, iniciadas oficialmente en 1932 (en 1935, en lengua portuguesa); la distribución, a inicios de los años 30, en varias ciudades latinoamericanas, de diversos títulos de magacines o revistas de divulgación moscovitas; la avatares locales de Intourist (1929); o las más antiguas difusiones fílmicas, corresponderían, de igual modo, a ámbitos a abordar como otros factores de los esfuerzos soviéticos y cominternianos en los terrenos de la gravitación ideológica y cultural en nuestra región. A la par con las actuaciones propias de la IC, otros recursos que sirvieron para la canalización de los envíos, contactos y relaciones, corrieron por cuenta de entidades como las Asociaciones de amigos de la URSS, el Socorro Rojo Internacional, la Internacional Sindical Roja (Profintern), entre otras. Al parecer, un rol preponderante en estos esfuerzos cupo a la VOLKS (All-Union Society for Cultural Relations with Foreing Countries), creada en 1925.
} 
sociedad. En este sentido, mutatis mutandis, la creencia en el valor y la potencialidad de la palabra impresa y del discurso codificado, en tanto instrumentos para la emancipación, hace de la historia del libro y la edición cominternianas un filón expectante de exploraciones y hallazgos en una coyuntura historiográfica nacional e internacional que hurga por dar nuevas respuestas a interrogantes conocidas y emergentes. Sólo como ilustración de esto, señalemos que es cada día más perentorio resignificar entre nosotros los fenómenos de la bolchevización y la estalinización, toda vez que siguen ocupando demasiado espacio las explicaciones unilaterales, conceptualmente pobres o de un maniqueísmo rayano en la propaganda en favor o en contra de la constelación de elementos que han conformado la cultura comunista.

Desde un punto de vista metodológico, también es pertinente alertar sobre la tendencia que, aún se mantiene, de estimar como constante y de plena uniformidad la actuación de la IC durante las poco más de dos décadas de su existencia. En particular, esta tendencia uniformizante se verifica cuando se abordan las relaciones del centro moscovita con sus secciones nacionales, prefigurándose a estas últimas como meras cajas de resonancia de lo resuelto por el Ejecutivo de la IC o del mismo PCUS. Claro es que los esfuerzos por dar dirección única a la actuación comunista en estas secciones no dejaron de manifestarse, práctica que, sobre todo, sobresalió en los momentos de redefiniciones y cambios de línea llevados a cabo por la Internacional en, a lo menos, tres instantes clave de su trayectoria; pero, a la par, y de modo creciente durante la década de los años 30, en los modos de implementación de las políticas de Frente Único, de Clase contra Clase o de Frente Popular, no dejaron de expresarse tensiones, desarrollos de particularidades, y la necesidad de adecuaciones que, sin alterar lo principal de las orientaciones oficiales, propiciaron estilos, visiones y conductas que, en lugares y coyunturas específicas, aportarían ingredientes "propios" a la cultura política comunista.

Con relación a lo dicho en el párrafo precedente, considero que la historia intelectual y de los medios de expresión social -verbigracia, de la edición y del libro- permiten auscultar de modo adecuado "otra cara" de la trama habitual de registros sobre el pasado de la IC (organismos y estructuras, emisarios, resoluciones, reconvenciones, destituciones, disputas, conspiraciones, relatos de memorias y desencantos, etc.) Buscamos, en consecuencia, contribuir a una historia cultural y social de la Internacional en Latinoamérica teniendo como objeto el análisis de la producción, distribución y recepción del libro cominterniano en los tipos primordiales del folleto y monografía "científicas"; la edición de documentos, y la literatura de ficción. Si bien los tópicos indicados llevan obligatoriamente a la confección de catastros y cartografías de circulación, nuestra atención también estará puesta en identificar a los individuos y acciones que articularon este quehacer, sea de los que gestionaron y administraron, como de los que propusieron e hilvanaron una cierta política editorial cominterniana.

No obstante nos abocamos aquí al libro comunista regional de algún modo vinculado a la Comintern, es imprescindible acotar que, en varias ocasiones, esta producción y circulación se verificó en el contexto de una tradición editorial inherente a la aparición y 
trayectoria de las organizaciones obreras y políticas de izquierdas -comunistas y no comunistas- de este lado del mundo, es decir, en conexión con los recursos y experiencias preexistentes ${ }^{5}$. Por lo mismo, al hablar de la edición cominterniana en nuestros países, se debe tener el cuidado de no suponerla al margen de las prácticas y antecedentes editoriales pasados o en curso; al contrario, frecuentemente las acciones cominternianas se llevaron a cabo con o por medio de empresas, capitales y fuerza de trabajo locales, en oportunidades, plenamente partidarias, en ocasiones, de particulares con distintos niveles de compromiso político. Incluso, en países de mayor potencia editorial, como eran Argentina, México o Brasil, la comparecencia de la mera conveniencia del negocio guio la labor de algunos individuos sin que estos fuesen ni medianamente simpatizantes con el comunismo. Nuestro esfuerzo, en todo caso, se dirigirá a ubicar y caracterizar los emprendimientos donde la aparición de la Internacional fue más nítida, criterio que nos proporcionará más claramente noticias sobre la valoración de lo editorial en la acción política, sus orientaciones y decisiones 6 .

La historia del libro comunista regional en el siglo $X X$, cuenta, a la fecha, con un grupo ascendente de trabajos, especialmente artículos científicos, libros y capítulos de libros7. También es posible consultar algunas monografías que, al tratar de temas de historia intelectual o política, se han aproximado con alguna detención en los asuntos editoriales. Probablemente la nota más relevante de este quehacer sea que, con distintos niveles de logro, disponemos de acercamientos para buena parte de A. Latina. De esta suerte, apariciones de acápites centrados en México, Costa Rica, Brasil, Argentina, Chile, Uruguay -por citar sólo a los que hemos tenido acceso- auguran un buen despliegue de la temática. Se trata, en general, de comunicaciones que dan cuenta de indagaciones hechas a base de las informaciones que, en su momento, aparecieron en las páginas de revistas y de la prensa partidaria y sindical de filiación comunista, datos que, en secuencia temporal, han permitido ir identificando títulos, autores, tendencias temáticas, formas de distribución, mecanismos de gestión, etc. De igual forma, la consulta en archivos, bibliotecas y registros oficiales, tanto

\footnotetext{
${ }^{5}$ No debemos olvidar que, a la par con el ejercicio editorial autóctono, y el que luego oficiará la Comintern, también se dio en nuestros países la afluencia, por vías formales e informales, de variados productos monográficos de filiación socialista confeccionados por editores españoles o franceses. Muchas veces, a base de estos textos, se propició un comercio de sueltos y folletos breves de contenidos muchas veces arbitrarios, sin reconocimiento de autor o fuente. Su presencia, probablemente notoria en varios momentos, alertó a autoridades civiles y eclesiásticas, llevándose a cabo razias policiales y confiscaciones a fin de eliminar las octavillas "pornográficas" y "subversivas".

${ }^{6} \mathrm{Si}$ bien, como se indica, nuestra mirada estará puesta en la actividad editorial del período de la Comintern, numerosos antecedentes posteriores, tanto bibliográficos como culturales en general, pueden consultarse en Tobias Rupprecht, Soviet Internationalism after Stalin. Interaction and Exchange between the USSR and Latin America during de Cold War, Cambridge University Press, UK, 2015 y, más recientemente, en Vijay Prashad (editor) The East was read. Socialist Culture in the Third World, LeftWords Books, New Delhi, 2019

7 La comunicación impresa del comunismo latinoamericano involucra, a su vez, los ámbitos de las revistas, y de la prensa diaria y periódica. Como se ha dicho, aquí sólo nos ocupamos al área monográfica o del libro y sus formatos. Desde el punto de vista del tratamiento historiográfico, su situación es muy similar a la que apuntamos respecto del libro, sobresaliendo la producción del Dr. Ricardo Melgar Bao en materia de revistas y otras publicaciones seriadas. Al respecto, ver de Melgar: La prensa militante en América latina y la Internacional Comunista, Instituto Nacional de Antropología e Historia, México DF, 2015
} 
gubernamentales como policiales, también han surtido de datos a los textos aparecidos preferentemente en la última década ${ }^{8}$.

Con todo, este ámbito de estudios adolece aún de limitaciones que esperan superación. En efecto, tratándose de un tópico nuevo en nuestro medio, es claro que todavía no se cuenta con un perfil metodológico consistente a fin de sobrepasar lo puramente descriptivo, así como de proponer investigaciones que estén en sintonía con los debates epistemológicos que, desde hace unas décadas, intentan fundamentar la historia del libro9. Tampoco se ha avanzado en trabajos que vayan más allá de lo puramente nacional o de experiencias editoriales locales ${ }^{10}$. De igual manera, los resultados hasta ahora conocidos no han considerado los antecedentes presentes en los archivos oficiales rusos de la época que nos ocupa, en especial de la Internacional Comunista y de otras instancias similares. Sin duda que valioso también resultaría disponer, a pesar de las dificultades que rodea el asunto, de datos pertenecientes a las principales editoriales del período soviético y de su intensa actividad traductora y distribuidora. Algo similar debería inquirirse respecto de las primeras editoriales comunistas españolas y su presencia en Norte y Sudamérica. Por su parte, resta ampliar las indagaciones en archivos policiales y de la seguridad interior de los gobiernos y Estados de esta parte del mundo. No menos importante, sería consultar archivos de constitución de sociedades comerciales, así como el tratamiento de varios centros de documentación y bibliotecas pertenecientes a antiguos militantes y dirigentes del comunismo regional. La historia editorial y del libro, sea en general como en particular, concita la atención de numerosas áreas de la actividad social, y sus alcances no sólo atingen a asuntos intelectuales, de lectura, ideológicos, de gustos, modas, tendencias, de recepciones y usos, de redes, contactos y colaboraciones, sino, a la vez, de modalidades organizacionales, de gestión, de producción, de mercado, financiamiento y distribución. Es decir, el hecho editorial y sus modos de existencia - y el libro comunista es un ejemplo de ello- bien puede ser considerado un panóptico para el examen multivariado de un sinfín de hechos y entidades históricas.

\footnotetext{
8 Algunos recursos consultados, son: Hernán Camarero, A la conquista de la clase obrera. Los comunistas y el mundo del trabajo en la Argentina, 1920-1935, Siglo XXI, Buenos Aires, 2007; Marisa Silva, Aquellos comunistas (1955-1973), Taurus, Montevideo, 2009; Gerardo Leibner, Camaradas y compañeros. Una historia política y social de los comunistas del Uruguay, TRILCE, Montevideo, 2011; Olga Ulianova y Alfredo Riquelme, edits., Chile en los archivos soviéticos, 1922-1991, 3 volúmenes, DIBAM-Centro Barros Arana, Santiago, 2005-2017; Horacio A. López, Las editoriales rojas: de La Internacional a Cartago, Ediciones Luxemburg, B Aires, 2018; Adriana Petra, Intelectuales y cultura comunista. Itinerarios, problemas y debates en la Argentina de postguerra, FCE, B. Aires, 2017; Marisa Midori Deaecto y Jean-Yves Mollier, Edicão e revolucão. Leituras comunistas no Brasil e na FranÇa, Ateliê Editorial, Editora UFMG, São Paulo, 2013; Hebe Clementi, Lautaro. Historia de una editorial, Leviatán, B. Aires, 2004; Patricio Herrera y Santiago Aránguiz, edits., El Comunismo en América Latina. Experiencias militantes, intelectuales y transnacionales (1917-1955), Universidad de Valparaíso, Valparaíso, 2017; Nicolás Acevedo, Un fantasma recorre el campo. Comunismo y politización campesina en Chile (1935-1948), Ed. América en Movimiento, 2017 Elvira Concheiro, "Repensar a los comunistas en América Latina, revista Izquierdas, 7, año 3 (2010), pp. 1-19. Recientemente Rodolfo Porrini ha publicado Montevideo, ciudad obrera. El 'tiempo libre' desde las izquierdas (1920-1950), CSIC, Universidad de La República, Montevideo, 2019

9 D.F McKenzie, Bibliografía y sociología de los textos, Akal, Madrid, 2005; Roger Chartier, “Textos, impresão, leituras", en Lynn Hunt, A Nova Historia Cultural, Martins Fontes, São paulo, 2001; Robert Darnton, "Historia da leitura", en Peter Burke, organizador, A Escrita da historia. Novas perspectivas, Editora Unesp, São Paulo, 1992; Marc Angenot, Interdiscursividades. De hegemonías y disidencias, Editorial Universidad nacional de Córdoba, 2010 10 Una excepción a esta regla es Midori et.al., op.cit.
} 
En este mismo sentido, no perdamos la oportunidad para agregar que la historia del libro y el correlato editorial e intelectual que le es inherente, es un campo propicio para responder a la actual demanda de una labor historiográfica de pretensión transnacional. Si bien ello -por condicionamiento metodológico y por disponibilidad de recursos- no es nada sencillo, en nuestro caso, la propia naturaleza internacional de la materia, insta a la ampliación de los enfoques a fin de tender a la comprensión adecuada del problema que nos hemos propuesto.

Como se indicó al comienzo, este texto entrega una visión preliminar de la gestión editorial de la IC en nuestra región. De esta forma, luego de la exposición sobre cómo fue instalándose la temática del quehacer editorial en las directivas centrales de la IC en el transcurso de sus primeros lustros de existencia, avanzaremos a la indicación de las circunstancias que rodearon la aparición de la edición cominterniana propiamente latinoamericana. Finalmente, junto con ensayar algunas conclusiones sobre lo obrado, sugeriremos otras tantas perspectivas que se abren para el tema.

En nuestro imaginario colectivo, el libro es un soporte natural de las culturas políticas, en particular en las de matriz socialista. Desde sus orígenes, la propaganda y la difusión de sus tácticas y visiones de mundo, fueron asuntos de primer orden en la Internacional Comunista. Para ello, entre otros medios, puso en marcha unos Servicios de Edición donde la gestión y materialidad de los propósitos hubo de colocar en escena nociones modernas de la agitación y la propaganda, según orientaciones leninistas. Según estas, los partidos comunistas -partidos de nuevo tipo-, a la cabeza del proletariado, debían estar compuestos de revolucionarios profesionales e íntegros, de lo que se colegía la importancia que debía darse a la formación ideológica y política de estos cuadros. A su vez, en cuanto a las masas, su conducción hacia los cambios y la revolución, requería, además de su organización, una constante prédica y, en lo posible, un acercamiento efectivo a nociones y rudimentos ideológicos generalmente simplificados, abundantemente nutridos de imágenes y expresiones redentoristas donde la orientación a un fin salvífico, no dejara de mostrar los signos del mal, la explotación y la abyección moral a que ellas habían estado sometidas. En los hechos, desde el punto de la producción gráfica, rápidamente se fue conformando una variedad de consumos previstos por los trabajos de apresto de la narrativa socialista, medianamente formalizados en la gramática clasista, y las hojas y carteles de recursos impresionistas (consignas, formas, color, reiteraciones) expresamente funcionales a públicos de escasa o ninguna cultura letrada, frecuentemente más imbuidos en la comunicación oral, la tradición mítica, o las creencias religiosas.

Las propias 21 condiciones de adhesión a la Internacional disponían, cuál más cuál menos, de una relación estrecha con los asuntos y actividades de la propaganda y su difusión amplia, propiciándose así una tendencia que veía en la letra de molde a un elemento sine qua non de su propio rol internacional. A pesar de ello, los Servicios de Edición, al menos durante el primer lustro de la IC, estuvieron caracterizados por un quehacer de baja intensidad a raíz de la propia complejidad que significaba la tarea de regimentación discursiva que sólo sobrevendría con los llamados procesos de bolchevización. De este 
modo, no es difícil notar que, hasta mediados de los años 20, la tarea editorial cominternista se realizó en paralelo y aprovechando bastante la gestión e intereses de difusión propios de cada sección y sus respectivas herencias literarias. Sólo a contar de los años 1926-27, comenzará a verificarse un incremento de las ediciones bolchevizantes y sovietizantes, en especial en su dimensión más plenamente formativo-propagandísticas. No obstante, ello tampoco redundó en una total desconexión con prácticas y preferencias previas. Antes que la desaparición o subordinación de estas últimas, lo que hubo -según datos que hemos detectado en las situaciones de Argentina o Chile- fue la cohabitación de ambas funciones difusionales, complejizándose, en cierta medida, el panorama editorial de las izquierdas de comienzos del siglo XX.

Que esta mezcla de lo anterior y lo nuevo tuvo un alcance general, lo prueba lo ocurrido entre los comunistas franceses a poco de haberse creado su partido (1920). En efecto, en una producción bibliográfica que seguía dando cabida, en sucesivas tiradas, a numerosas obras de políticos e ideólogos del socialismo finisecular -además de frecuentes autores de ficción- en pocos años tal acervo será completamente descartado por los nuevos criterios de edición. Así, por ejemplo, a la par de folletos de Charles Rappoport o Jean Jaurés; se dará cabida no sólo a $A B C$ del comunismo, de N. Bujarin, sino también, en 1924 a Los fundamentos del leninismo, de José Stalin, en calidad de manual de vulgarización ${ }^{11}$. En los hechos, más allá de la mantención en los catálogos de algunos textos de Marx, en Francia, España, y casi simultáneamente, en México o Argentina, se tendió a sustituir los clásicos o populares vernáculos, por nuevas líneas de productos signadas por los encabezados de Pequeña Biblioteca Marxista o Anaquel Leninista.

Al son de las líneas y orientaciones de orden universalistas que el estado mayor de la IC fue propugnando, emergería también la necesidad de contar con medios de difusión y propaganda acordes a los nuevos requerimientos del horizonte revolucionario en ciernes. En consecuencia, y de modo cada vez más notorio, las resoluciones y acuerdos de reuniones y torneos cominternianos fueron suscitando una acción editorial no sólo más nítida en cuestiones de temas y autores prioritarios, sino, a la vez, en asuntos de tipos de impresos, financiamiento, colecciones y distribución, prefigurándose públicos y formas de acercamiento a los contenidos. El impreso, en sus distintos formatos y modulaciones, debía ir colocándose abiertamente a favor de los objetivos revolucionarios.

En directa consonancia con los debates y conclusiones que llevaron a la llamada bolchevización de la Comintern y sus secciones nacionales, el V Congreso de la IC (1924) marcaría una suerte de punto de partida de una propuesta editorial que apuntaba a dotar a los comunistas del orbe de las herramientas teóricas y tácticas que les permitieran dejar atrás un sinfín de debilidades y desviaciones acusadas entre los partidos y masas obreras luego del triunfo del Octubre soviético. Por lo demás, a las derrotas, confusiones y discrepancias experimentadas primordialmente en el seno de las fuerzas socialistas europeas, se unía también la ingente incorporación de nuevas regiones y organizaciones a las luchas

11 El texto recoge una serie de conferencias que Stalin pronunció en la Universidad Sverdlov y publicadas en Pravda, en abril y mayo de 1924. Estas y otras intervenciones hechas en plena refriega por la sucesión tras la muerte de Vladimir Ilich, darán paso a más de un folleto estaliniano sobre el líder y su legado: Leninismo en teoría y práctica, Acerca del leninismo, Lenin y las conferencias Los fundamentos del leninismo, que fueron luego incluidos en el libro Cuestiones de leninismo. 
liberacionistas sin que tales empeños dispusieran de los conceptos y procedimientos de actuación demostrados acertados y necesarios de esparcir ampliamente. En palabras de los comentaristas oficiales del evento

Las ideas leninistas relativas a la asimilación de la experiencia bolchevique, sirvieron de base para las resoluciones del V Congreso, sobre el reforzamiento ideológico, teórico y orgánico de las secciones de la Comintern. Desde estas posiciones, precisamente, fijó las tareas concretas de la bolchevización, entendiéndose por ella, el largo y complicado proceso de forjar el Partido Comunista verdadero y crear el movimiento revolucionario de masas bajo las banderas de Marx y Lenin, así como la capacidad de aplicar las tesis marxistas-leninistas al análisis de la realidad concreta ${ }^{12}$

Otra iniciativa relevante en la perspectiva de la modelación descrita, refirió a la creación y funcionamiento de sendas escuelas y universidades comunistas y de los trabajadores en la URSS, espacios que, con distinto éxito, y prolongándose entre una y dos décadas, acogieron a varios miles de adherentes llegados de India, Japón, países árabes, Indochina o Mongolia, además de otros tantos de regiones europeas ${ }^{13}$. Estudiantes latinoamericanos también acudieron a tales centros, no obstante, su cantidad fue comparativamente menor al de otras agrupaciones extranjeras.

Los cambios en los asuntos editoriales, implicó que la Sección de Ediciones de la IC, creada en 192214, pasó a depender del aparato central de Agit-Prop, al mando del húngaro Bela Kun (1886-1938). A esta instancia se le encargó desarrollar nuevas obras de divulgación, manuales y guías populares. La base de los contenidos a desplegar en distintos formatos, debía corresponder a una selección de textos de Marx, Engels y Lenin. Para 1927, Krebs informaba que los trabajos de edición de la IC estaban presentes en 40 países, publicando en 47 idiomas. Un par de años más tarde, se señalaba que, en 16 países, había 18 empresas editoriales vinculadas a la Internacional. Entre estas, las de mayor importancia correspondían al PC alemán que, el citado año, disponía de dos sellos editoriales: Verlag für Literatur und Politik, para las obras teóricas, y Neue Deutsche Verlag, vinculada al mundo sindical. Por su parte, hacia 1929, el PC inglés trabajaba con dos editoriales en Londres: Martin Lawrence Ltd, y Modern Books Ltd. En cuanto a los comunistas norteamericanos, desde 1924 tenían su propia estructura: la International Publishers, en Nueva York ${ }^{15}$.

Para algunos títulos e idiomas, en particular correspondientes a partidos que eran muy débiles o estaban reprimidos, la Internacional tomó directamente en sus manos la traducción, producción y despacho de impresos. Esta labor, no obstante, no fue algo

12 La Internacional Comunista, VVAA, Moscú, Ed. Progreso, s/f, p. 92 en

http://bolchetvo.blogspot.com/

13 Escuela Leninista Internacional (1926), Universidad Comunista de Trabajadores de Oriente (UCTO o KUTV, 1921), Universidad Sun Yat-sen (1925-1930), dirigidas por el CEIC de la Comintern

14 Desde este año hasta 1937, estos Servicios estuvieron dirigidos por el ucraniano Mijaíl Evseevitch Krebs (Kreps)

15 Marie-Cécile Bouju, Lire en communiste. Les maisons d'édition du Parti Communiste franÇais, 1920-1968, Presses Universitaires de Rennes, 2010; Jean-Numa Ducange, Julien Hage, Jean-Yves Mollier (edits.) Le Parti Communiste franÇais et le libre. Écrire et diffuser le politique en France au XXe siècle (1920-1992), Editions Universitaires de Dijon, 2014 
excepcional sobre todo desde finales de los años 20, momento en que, de modo creciente, los servicios de propaganda moscovitas y su soporte laboral y financiero importó tanto la producción propia, como la distribución de tareas y de gestión fuera de las fronteras soviéticas. Las secciones de Alemania, Francia y España estuvieron entre las más destacadas en colaborar activamente para nutrir de impresos a sus propios públicos, pero, también, para redestinarlas a otros puntos, como era América Latina. En esta cadena de acciones que, paulatinamente, fue in crescendo los asuntos de traducción a diversidad de lenguas fueron los de mayor preocupación a fin de asegurar fidelidad o la mala interpretación de los contenidos $^{16}$. De esta forma, fuese que los traslados idiomáticos se hicieron en Moscú o en otros puntos de Europa, era imprescindible que el nihil obsta dispusiera de la venia de los servicios centrales, medida que, aun así, no aseguró nunca un cien por ciento de efectividad ${ }^{17}$. Luego de expurgar lo estimado como malo o equivocado, los originales muchas con las indicaciones de tamaños, materiales de impresión, cantidad de cuartillas, foliación, número de ejemplares, etc.- se enviaban a una o más secciones nacionales para su impresión. En varios casos, incluso se sugirió a los gestores locales precios y formas de distribución. En síntesis, resultaba evidente que la burocratización y profesionalización que emprendió el quehacer editorial de la IC desde la segunda mitad de los años 20, también buscaba que la regimentación lectoral e ideológica en curso, pudiese ser controlada y cuantificada ${ }^{18}$.

Ahora bien, a la luz de las repetidas alusiones que en Europa y América latina se hacían respecto de aumentar y mejorar los niveles teóricos de la militancia, además de la mayor comprensión de las orientaciones de la Internacional, es que resulta bastante plausible sostener que, entre las variadas causas de ello, estuvieron las limitaciones que la IC demostraba para una actuación más coherente y homogénea. Por de pronto, en el área editorial y propagandística, no logró expulsar o transformar cabalmente las culturas editoriales y de lectura ínsitas en cada sección local. Las diferencias que se registraron entre

\footnotetext{
16 Según el suizo Jules Humbert-Droz (1891-1971, lentamente la IC se fue convirtiendo en un amplio aparato de refugio de traductores -y de otras tareas editoriales- que caían en la sospecha de alguna autoridad partidaria o estatal soviética (...) un último refugio para permanecer recibiendo algo de dinero.

17 En lo que tocaba al mundo occidental, el plan de ediciones de la IC para los años 1929-1930, contempló, en primer lugar, publicaciones en alemán. Seguían las de idioma inglés y, en tercer lugar, en francés. Tal como mencionaremos luego, una cantidad importante de las ediciones en español, fueron hechas a base de traducciones del idioma galo.

18 Un claro ejemplo del celo y control de la edición impresa, fue el protagonizado entre las Ediciones Sociales Internacionales (ESI), organismo creado en 1926, y la IC. A propósito del aviso de aparición en Francia (febrero 1927) de unas Obras completas de Lenin en 30 volúmenes (a razón de 4 por año) la IC conformó una sección leninista cuyos traductores oficiales en Moscú fueron P. Pascal y V. Serge. Su tarea se vio frecuentemente objetada, debiendo entregar en repetidas ocasiones nuevas versiones de lo hecho. Una vez aprobada la edición final (traducida), los originales se enviaron a Paris para su composición, regresando otra vez a Moscú para el visto bueno final, incluyendo diseño y textos de portada (Los costos, la falta de personal y las demoras, atrasarían la aparición de los volúmenes prometidos). Esta preocupación y revisiones sobre revisiones, no dejó de revelar "errores de interpretación", erratas y otros problemas de impresión, sobreviniendo tensiones entre la ESI y la IC. En 1929, la traducción al francés del libro de V. Molotov La edificación del socialismo se trabajó con el cotejo inmediato del folleto en ruso. Finalmente, señalemos que, en Paris, los editores competentes y dispuestos a asumir los riesgos, eran escasos: los costos no sólo podían ser políticos, sino también financieros, pues la IC, como rectora del imprimatur, podía solicitar correcciones aun cuando el texto ya estuviese compuesto, lo que resultaba oneroso.
} 
numerosos países, aun adentrados los años 30, en cantidades, autores, tipos de materiales o formas de distribución, dieron cuenta de que fue muy difícil materializar una política editorial uniforme, realidad que, en la práctica, llevó a una aceptación tácita de las diferencias. Si bien, en el papel, las funciones editoriales de las secciones nacionales dependían del servicio de ediciones de la Comintern, ello no privó de que ellas propiciaran iniciativas más independientes, sea en los terrenos de la producción de textos y folletos, como en el despliegue de vínculos formales e informales con organismos sectoriales (sindicales, juveniles, culturales) soviéticos, así como con entidades editoriales comunistas europeas. Junto con los Institutos Lenin; Marx y Engels, o las Ediciones Científicas Internacionales (ESI), de Moscú -alternativas particularmente utilizadas por las secciones europeas- las editoriales Cenit, Europa-América -relacionadas con el PC español- y la institucionalidad de la VOKS, fueron mayormente tratadas por los comunistas latinoamericanos ${ }^{19}$.

En el libro comunista -y la edición IC no fue la excepción- un papel destacado cupo a la literatura de ficción, la cual, con unos años de retardo respecto de las obras ideológicas, también hubo de experimentar las presiones de estilo y función derivadas de las concepciones que vieron en la creación un arma no menos adecuada para la formación militante y ciudadana del "hombre nuevo", tanto dentro como fuera de la Unión Soviética.

Algunos antecedentes recientes en torno a esta área ${ }^{20}$, observan que, desde inicios de la revolución de 1917, se produjo un intenso debate entre arte y política. Al igual que en asuntos de filosofía, el quid radicó en los caracteres y alcances de la creación en una coyuntura observada como decisiva en la lucha contra el antiguo orden. Organizaciones o adherentes a Proletkult (1917); la Asociación Pan sindical de escritores proletarios (VAPP,

${ }^{19}$ La prioridad dada a la formación de militantes bolcheviques, no impidió, en Europa y la URSS, la existencia de debates filosóficos sobre el marxismo, en los que participaron intelectuales de tendencias diversas. La cultura, y en especial la literatura, interesó menos al poder, si bien, hacia finales de los años 20, el estalinismo vendría a zanjar las discusiones. Para comienzos de los 30, la ortodoxia en temas de marxismo dialéctico e histórico había triunfado, constituyéndose en la nueva teoría del Estado y de las secciones. Se fortalecerá la teoría de las dos ciencias con la publicación de nuevos manuales. En los debates de los años 20, dos entidades coparon la discusión: el Instituto Marx y Engels (IME), y el Instituto Lenin. Para el bolchevismo, acaparar las obras de Marx en detrimento de los socialdemócratas, fue un imperativo. En el seno de las ediciones del Estado soviético (Gosizdat, 1920), se creó una comisión especial llamada Comisión Marx, que preparó una edición de obras de Marx y Engels prevista en 28 vols. La experiencia se detuvo provisoriamente en 1922. En 1921 se crea el IME bajo la dirección de David Borisovitch Goldendach Riazanov: La misión primera de la IME fue editar en alemán las primeras obras completas de Marx y Engels en la Marx Engels Gesamtausgabe (MEGA) con cerca de 40 vols. Este proyecto monumental fue presentado en 1924 en el V Congreso de la IC. Al tenor de este proyecto, Riazanov organizó la colección de archivos y los envía a Moscú. Con el incremento de los debates en torno al marxismoleninismo, Riazanov fue arrestado en enero de 1931, siendo reemplazado por Víctor Adoratsky. La llegada de los nazis al poder, desmantela a buena parte del personal científico interrumpiéndose la MEGA en 1935 con 1 vols. Publicados. Por su parte, la consolidación del marxismo-leninismo modificó la misión del IME, en 1931, iniciando su funcionamiento junto al Instituto Lenin, conformándose el I M E L, símbolo de la estalinización de la filosofía. Este proceso se corona en 1938 con la edición de Materialismo dialéctico y Materialismo histórico de Stalin (el Diamat estalinista)

Mientras, 1923, el PCUS había lanzado una nueva campaña de formación anunciado la publicación de las obras de Lenin a cargo del I Lenin. Una primera edición de sus Obras Completas (1927) con 24 vol; le siguió otra en 1937, con 31 vols.

20 Matthias Neumann, La Liga de las Juventudes Comunistas y la transformación de la Unión Soviética (1917-1932), Ariadna Ediciones, Santiago, 2019 
1921) o la Asociación de Escritores Proletarios de Rusia (RAPP, 1928), intervinieron no sin claras discrepancias, las que, progresivamente comenzaron a ser zanjadas por el PCUS y sus representantes de la educación y la cultura. Un momento culminante a favor del objetivismo y su rol formativo, estuvo en el primer Congreso de Escritores soviéticos (agosto de 1934), resolviéndose la abolición de las diferencias entre escritores proletarios y compañeros de ruta, lo que equivalía a la liquidación de posturas tildadas de individualistas y formalistas, presentes no sólo en espíritus burgueses, sino también, entre los simpatizantes de la izquierdista y utópica Proletkult. Lo que las circunstancias y las posiciones revolucionarias correctas requerían, se sintetizaría ahora en la noción de "realismo socialista", término difuso y, por lo mismo, políticamente peligroso, al permitir someter a la tutela del Partido el conjunto de las artes. Esta senda política y literaria, fue conocida en el extranjero gracias a varias entidades utilizadas por la URSS y la Comintern, las que, en general, buscaron llamar la atención del público partidario y no comunista. La citada VOKS y sus diversas dependencias, además de la amplia institucionalidad cominterniana, se proponían así un despliegue ideológico y publicitario que, a pesar de sus déficits y limitaciones, contribuyeron a esparcir el verbo y la imagen de la patria socialista.

Tiempo antes, cuando, a nivel internacional, aún se mantenía el brillo de la actuación de los comunistas rusos, el IV Congreso de la Comintern (1924) había dado su respaldo a la creación de la Unión Internacional de Literatura Proletaria, y a un Buró para las relaciones con escritores cercanos a la IC, intentando promover el desarrollo de la literatura proletaria en Occidente, con la ayuda de los respectivos PC y de la VAPP (Asociación Panrusa de Escritores Proletarios, organización Proletkult). Igualmente, la IC participó en la organización del Congreso de Escritores Proletarios en Kharkov, en noviembre de 1930, ocasión en que se reemplazó el Buró antes citado por La Unión Internacional de Literatura Proletaria (UIER). Uno de sus principales objetivos fue difundir en el mundo la joven literatura soviética. A partir de 1932, y luego de la disolución de la VAPP, la UIER fue concentrándose en la lucha contra la guerra y el fascismo. Para comienzos de los años 30, el control del Estado soviético sobre las organizaciones culturales, científicas y editoriales era considerable. El autor, estatizado e institucionalizado, era ahora -según lo dicho por Stalinun "ingeniero del alma", y nada alejado de tal prurito estuvo la convicción de la IC de ver en el libro, y en el impreso en general, útiles herramientas para la educación y la introyección políticas.

Pero la decisión de hacer de los textos un apoyo primordial de la revolución proletaria mundial no era un asunto conseguible en breve plazo. La idea y la voluntad debían hacer frente a un conjunto de trabas que, en lo que toca a América Latina, aparecían más notorias. Desde luego, las prácticas lectoras eran escasas y ajustadas comúnmente a los sectores con algún nivel de alfabetización, lo que, de entrada, dejaba fuera a buena parte de los adherentes y simpatizantes izquierdistas. También, la abstracción y complejidad que las categorías del discurso transformador y contestatario de base marxista proponían, no alentaban a un acercamiento a este tipo de literatura. Conste, además, que hacia los años 30, la gramática y analítica cominterniana con sus propuestas clasificatorias de zonas, naciones, etnias y otras construcciones de colectivos sociales, asomaban como una ingeniería cuya nomenclatura y ubicación dentro de la misma, no hacían sino trastornar las nociones habituales de ricos y pobres y sus recurrentes representaciones y usos en la vivencia política 
de los sectores populares. A este respecto, basta con que recordemos que prácticamente toda la simbología gráfica ejercitada por las distintas corrientes del socialismo primigenio regional, hundía sus raíces en la dicotomía del bien y el mal de matriz cristiana.

A las resistencias citadas, se agregaban -aún más en Latinoamérica que en Europaotras dificultades, tales como los requerimientos financieros, las distancias con los centros proveedores, disponer de personal calificado y de confianza, contar con infraestructura de impresión, con modelos de precios y sustentación, con definiciones de productos y colecciones, con medios de traslado y acopio, de distribución, librerías y difusión. Tampoco fue fácil determinar las instancias responsables del quehacer según tipos de materiales y públicos destinatarios; si la labor editorial tendría sus propias estructuras y encadenamientos, a la par de tratar de responder a las demandas surgentes de cursos y escuelas de capacitación para habilitar en hábitos y conceptos a la primera línea de la potencial masa lectora: la dirigencia y militancia comunista. Y, no menos relevante, intentar hilvanar una gestión editorial en medio de frecuentes represiones, asaltos e incautaciones, realidad que llevó a las consiguientes inseguridades de la clandestinidad.

Por sobre los recelos ideológicos y las autonomías propias del negocio, frecuentemente las directivas políticas e editoriales de la Comintern tuvieron que transigir con la capacidad instalada de la cultura editorial y empresarial de fuera de la URSS, experiencia que no dejó de reportarle a ella y al propio Estado soviético más de un aprendizaje y perfeccionamiento sobre cómo administrar internacionalmente su propio patrimonio de industria cultural. Sobre los avatares y entresijos de personajes, acuerdos, distanciamientos, sospechas, auges y caídas que rodeó la expansión de la edición soviética y cominterniana apoyándose en editores, imprentas, distribuidores y hasta especuladores de Francia, España o Italia a partir de mediados de los años 20, la bibliografía acumula varios títulos, no así en lo dice a nuestra región. Por cierto, la ausencia de datos puede deberse no sólo a lo que ya apuntamos en cuanto a las importantes limitaciones del medio lectoral marxista regional; no obstante, también se observan omisiones a la luz del siempre bajo atractivo que América Latina tuvo para las casas editoriales españolas, y esto no únicamente respecto del libro comunista, sino también de otras ofertas y catálogos.

En torno a lo dicho, y más allá de los elementos adversos, el folleto y la monografía de patrocinio o interés partidario, no sólo tuvo presencia, sino interés creciente en nuestros países, sin alcanzar, por cierto, un caudal medianamente importante en la circulación pública de impresos ${ }^{21}$. Esta relativa mayor significación sobrevendrá debido a la conjunción de varios hechos que tuvieron lugar durante los años de existencia la IC. Desde luego, la relevancia y expectativas abiertas con el triunfo de la revolución soviética, motivó inquietud y avidez por saber más sobre las ideas socialistas. Luego, la rápida constitución en nuestro medio de organizaciones sindicales, maximalistas y comunistas que pronto buscarían adherir a la Internacional y demás órganos funcionales, también alentaron la construcción de un público disponible para el folleto revolucionario, circunstancia que tendría su mayor

${ }^{21}$ Hasta bien entrado el siglo XX, los textos e impresos de base o autoría marxista, siempre ocuparon lugares de rezago en los mecanismos generales de circulación librera en la región. Sólo con el arribo de los años 60 y la transformación del campo intelectual, literario y editorial, el texto marxista dispondrá de una visibilidad y consumo mayores, pero sin que nunca haya prevalecido de modo ostensible. De otra parte, si comparamos al folleto revolucionario con la prensa diaria y periódica, la proporción de este alcanza niveles aún más marginales. 
dinamismo entre quienes, por capital cultural, podían acceder con menos dificultad a estos contenidos: estudiantes, intelectuales, profesionales, etc. Tampoco podemos dejar de aludir a la gradual multiplicación de iniciativas de impresión y divulgación de textos que, con el inicio del siglo XX, fue ampliando y rivalizando el campo de la publicidad tradicional. Con ello, el discurso público no sólo se fue volviendo más polifónico y plebeyo, sino también, se fue forjando profesionalizando y especializando en la figura del editor que bien podía unir en sí -o en pequeñas cofradías- las cualidades de la administración con las del creador y curador de contenidos.

Quizá si en el campo de las revistas culturales, con importantes cuotas de inquietudes sociales y políticas, es donde mejor podemos ubicar y sintetizar aspectos relevantes de la descripción de hechos que hicimos en el párrafo anterior, pues, a base de varios de los recursos y fortalezas que ellas y sus gestores capitalizaban hacia finales de los años 20, fue que concurrieron a aportar -no sin provecho comercial- a las necesidades de expansión de la publicidad y propaganda comunistas. Por si fuera poco, la coyuntura de la política internacional, así también lo favoreció. En efecto, a la necesidad de conformar destacamentos comunistas doctrinaria y tácticamente bien pertrechados -bolchevizadoscon el inicio de la década de los 30, Europa y América Latina experimentarán convulsiones de desenlaces catastróficos. Ahora bien, los interrogantes, inseguridades y desafíos que el período concitó, redundarían, entre otros efectos, en una "fiebre por la lectura", afán que, en el terreno político e intelectual, influiría en la necesidad de contar con más Marx y más Lenin, así como con más documentos, discursos, revistas y panfletos.

Ateniéndonos a los esfuerzos específicos de generación de un órgano con cobertura latinoamericana de producción y distribución de libros por parte de la Comintern, debemos decir que, hasta el momento, sólo podríamos reconocer un solo emprendimiento en tal sentido: el que se llevó a cabo a través del PC de Uruguay, Ediciones Pueblos Unidos, creada en 1942, es decir, cuando la IC ya expiraba. Este hecho, más la aparición de sus primeros títulos un par de años más tarde, nos hace concluir que, durante toda la existencia de la Comintern, no hubo ninguna actuación editorial institucional que contuviera al conjunto de esta parte del movimiento comunista internacional ¿Fue posible o pensado un intento tal en las décadas precedentes? Al parecer sí, pero no hubo expresiones concretas. Lo que sí ocurrió fue que su accionar fue eminentemente pragmático tal vez si por las condiciones del medio editorial regional ya comentadas, las mismas que, en algún sentido y proporción, tuvieron que ver con el despunte de la paradoja siguiente: en atención a la centralidad y estrictez que siempre mostró el órgano rector del comunismo en materias de pautas orgánicas e ideológicas, este pragmatismo en asuntos editoriales asomó como un contrasentido. Desde nuestro presente, esta suerte de incoherencia, lejos de poner tacha a la actuación comunista, más bien podría discurrir por el ancho camino del realismo que privilegia los objetivos por sobre la pureza de los medios. Es más, incluso nos atreveríamos a postular que el ejercicio de lo factible por sobre lo perfecto, brindó los espacios para la aceptación tácita de más de alguna herejía política y editorial en el comunismo cominterniano regional.

El pragmatismo acusado se reflejó en las múltiples vías de producción y distribución de folletos, actuación que consideró mecanismos partidarios e institucionales, así como agentes privados con distintos niveles de formalización comercial y variedad de opciones 
ideo-políticas. En particular, esta última modalidad, sobre todo en cuestiones de distribución, implicó la inclusión de autores y libros que estaban al margen de la dogmática marxista-leninista. Obviamente, la necesidad de llegar a librerías y servicios de novedades con reconocimiento público la oferta marxista, obligaba a la vista gorda o a aceptar los términos impuestos por los dueños de los canales de despacho.

En los hechos, la provisión de productos fue dibujando modos de producción y diseminación que dejaba en manos de las secciones nacionales la folletería menor y de uso primordialmente militante (cursillos de formación, informes, discursos, revistas, boletines) $\mathrm{y}$, en manos de empresas, con o sin participación de dineros e intelectuales comunistas, los trabajos de impronta literaria de presumible mayor atractivo social, fuesen estos teóricoideológicos o de la estética del realismo socialista. Fue en esta arista que prevaleció, al menos hasta 1936, la mediación y control que tuvieron las editoriales comunistas (o de incidencia comunista) españolas respecto de nuestra región. A pesar de que la prevalencia de estas en nuestro medio nunca fue completo ni absoluto, el prestigio de sus traducciones, los contratos que habían hecho con los administradores oficiales de los derechos de las obras de Lenin, Marx, Lenin o Trotski, además de los nuevos narradores soviéticos, pasando por la capacidad que demostraban para manejar el siempre complicado negocio de la distribución, brindaba a sellos como Jason, Espasa-Calpe, Cenit o Ediciones EuropaAmérica, o a distribuidores como La Compañía Iberoamericana de Publicaciones, CIAP por citar a los más relacionados con la Comintern- un peso específico que los arrestos editoriales latinoamericanos no estaban en condiciones de rivalizar. Sólo el cambio radical de condiciones, acaecido con la derrota de la República española en 1939, impondría repensar a América Latina como espacio para propiciar una gestión editorial comunista más consistente.

Otro hecho que marcó la heterogeneidad y el pragmatismo editorial se debió a que buena parte de la institucionalidad funcional cominterniana que, de modo directo o indirecto se hizo presente entre nosotros -nos referimos a filiales, comités, ligas del Socorro Rojo, Internacional Sindical Roja, Internacional de la Juventud, Internacional Campesina, Amigos de la URSS, Liga Antimperialista Latinoamericana, Confederación de Trabajadores de América Latina, entre las más conocidas- confeccionó de igual modo sus propias ediciones, buscando responder a necesidades comunicacionales locales o puntuales. Esta variante de igual forma daría espacios a compañeros de ruta o a relaciones de conveniencias que, no pocas veces, poco o nada tenían que ver con el oficialismo ${ }^{22}$. Entre estos impresos, abundaron los boletines, las reproducciones de conferencias, discursos, almanaques obreros, y un sinfín de hojas y sueltos conmemorativos, grabados y litografías. La utilidad y valor de los mismos no debe desdeñarse en una historia comunicacional como la nuestra,

22 Un caso bastante nítido de disonancia fue la amplia crítica que La Correspondencia Sudamericana, órgano oficial del Secretariado Sudamericano de la IC, realizó del artículo "La situación continental", aparecido en el número 18 de El Libertador (publicación de la organización antiimperialista y de frente único Manos fuera de Nicaragua, México), ver "La revolución proletaria en América", en La Correspondencia Sudamericana, 4, 15 septiembre 1928, 2da época, p.4. De igual forma, en los años 30, y en varias oportunidades, la prensa comunista chilena expuso reparos de distinto tono sobre la pertenencia a ella, o la aparición en sus informativos, de personas o autores de dudosas credenciales democráticas e izquierdistas. Ver, Manuel Loyola "A associação de amigos da União Soviética no Chile 1927-1943”, en Estudos Iberoamericanos, 1, 42, 2016, DOI http:/ /dx.doi.org/10.15448/1980$\underline{864 X .2016 .1 .21647}$ 
en la medida que ellos, en su simpleza y multiplicidad, fueron vectores de primer orden para la difusión de mensajes, la construcción de referencias y la inevitable cacofonía que está a la base de todo proyecto político de masas.

\section{V}

Como proyección de la actividad impresora que caracterizó al conjunto de la cultura obrera regional de entre siglos, las secciones comunistas no cejaron en promover la conferencia y la lectura como herramientas de ilustración y lucha ${ }^{23}$. De ahí que, en lo local, como desde las instancias de dirección supranacional (burós y secretariados de la Comintern), se emprendieran trabajos en vistas a contar con un amplio abanico de vocerías impresas, tal como hemos comentado hasta aquí24.

En lo que tocó estrictamente a la IC y sus nodos de comando en nuestra región, con regularidad las críticas y autocríticas acerca de las fallas organizacionales o sobre no acertar con lo que se suponía indicado para tal o cual situación, iban acompañadas, por parte de las estructuras inferiores, de solicitudes de capacitación política y pedidos de literatura ad-hoc en calidad de contribuciones, sino imprescindibles, a lo menos relevantes en orden a las mejorías ${ }^{25}$. Todo apunta a constatar que, a pesar de las idas y venidas sobre el tema, a las direcciones superiores de la Comintern en Latinoamérica, les costó mucho proporcionar una respuesta medianamente satisfactoria a todo esto: sus prioridades eran otras ${ }^{26}$, los recursos

${ }^{23}$ La producción impresa, en general, de las fracciones u organizaciones que fueron antecedentes inmediatos de los partidos comunistas, y los productos que estos produjeron hasta las inmediaciones de 1925, constituye un acervo que, en lo que toca al Cono Sur, aún no cuenta con un estudio adecuado. Sobre este punto, existen series de enorme interés, como Documentos del Progreso, auspiciada por el PSI argentino entre 1919 y 1921, o los folletos de las prensas del periódico La Internacional, de Buenos Aires. Un acercamiento está en mi trabajo "Lecturas rojas: libros y folletos comunistas en Chile, 1920-1926", en Hernán Camarero y Manuel Loyola, Editores, Política y cultura en los sectores populares y de las izquierdas latinoamericanas en el siglo XX. Ariadna Ediciones, Santiago, 2016

24 Si bien en lo que sigue haremos mención sólo de algunas iniciativas conocidas y con auspicio oficial de las jefaturas comunistas (en sus diversos radios de injerencia), no debemos perder de vista que hubo un sinnúmero de impresos que, no por no disponer de la anuencia partidaria, deben quedar fuera de nuestra óptica analítica. Las maneras tradicionales de organización, más proclives a lo situacional y propio de cada agrupación, mantuvo una relativa autonomía comunicacional sin que varios de sus productos, por su bajo tiraje, oportunidad de contacto y/o distancia geográfica, fuesen siquiera conocidos en las cabeceras comunales, zonales o nacionales. Esta realidad y dinámicas persistieron por largo tiempo, a pesar de los avances que, en su momento, alcanzara el verticalismo organizacional. Es muy probable, a la vez, que, por los motivos ya anotados, muchos de aquellos impresos, al quedar al margen del registro público, no podamos nunca conocerlos.

${ }^{25}$ Un fragmento de una nota del SSA al PC de Chile de 25 de enero de 1927, señalaba: "Se resuelve escribirle a Vargas para que insista ante el CC a fin de que traten la cuestión de la Editorial que sería de gran importancia para la educación política del Partido. Se deja establecido que (...) Secretariado Sud-Americano, para fortificar la organización del Partido de Chile y hacer desaparecer dificultades que tienen los compañeros por el envío de los materiales y documentos en idiomas extranjeros, se les enviará traducidos al español los principales materiales, lo que se hará igualmente a los otros partidos sudamericanos". "Reunión del secretariado Sudamericano", en Víctor Jeifets y Andrey Schelchkov, América Latina en los archivos de la Comintern en Moscú, Academia de Ciencias de Rusia-Instituto de Historia Universal, Ariadna ediciones, Santiago, 2019 p. 776

26 Sin aludir a las prioridades propiamente ligadas a las luchas sindicales o de bolchevización, en la dimensión comunicacional que nos ocupa, ellas corrieron más por cuenta de la prensa pública: periódicos, semanarios (u otras periodicidades) con pretensiones de público variado y amplio. Para ello, se puso en juego el elusivo 
resultaban insuficientes, no se contaba con personal preparado, la tarea de la traducción al español avanzó muy lentamente27, las circunstancias del contexto político no eran estables, los empeños no tenían ninguna seguridad de éxito, las rencillas y cambios en los aparatos dirigentes también impedían una propuesta consistente. Como ya se señaló, esta ineficacia fue, sobretodo, en el plano macro-regional, tornándose la actividad más promisoria tanto a nivel nacional como en las irradiaciones más próximas a los centros de Buenos Aires o México.

Sobre las ediciones de los Secretariados Sudamericano $\left(\mathrm{SSA}^{28}\right)$ y del Caribe ${ }^{29}$ de la Internacional (México, Centro América, Cuba, en ocasiones se incluye, a la vez, a Venezuela

concepto de "prensa obrera o periodismo obrero". Por responder a importantes antecedentes comunicacionales previos, por servir de mejor manera a los fines organizacionales y de opinión, es decir, por estar mejor insertos en una cultura impresa altamente valorada, fue que, por lejos, los productos periodísticos y cotidianos coparon mayormente la atención de las agrupaciones y directrices comunistas durante todo el siglo XX. Para finales de los años 20, ello se tradujo, por ejemplo, en la aparición frecuente de títulos de órganos de la prensa diaria comunista en revistas $\mathrm{u}$ otros medios del Secretariado Sudamericano.

27 Sin que se pueda decir nada tan taxativo, llama la atención que en La Correspondencia Sudamericana sobresalga la oferta de textos en francés por sobre los folletos en español, cuya difusión era comparativamente menor. Así, en varias ediciones de su segunda época (1928), se indica que La Correspondencia “tiene en su administración una colección completa de todas las obras de importancia teórica y política sobre el movimiento comunista internacional. Publicaciones en francés editadas por el Bureau de Ediciones de París". Detalle:

Teoría

Le 18 Brumaire de Louis Bonaparte, de Karl Marx; L'Economie Mondiale et L'imperialisme, N. Boukharine; L'Economie de la periode de decli du capitalisme apres la Stabilisation, E. Varga; Principes du Communisme, Frédéric Engels; Les ennemis du paysan, Ernest Montusés; Contre le courant, N Lenine

Rusia: La religión au pays des soviets, J.F Hecker; Ou va la Russie?, P. Guiboud-Ribaud; La politique des soviets en matiere criminelle, N. Krilenko; Dix Annes d'edification economique en URSS, C.M. Krjijanovsky; En Russie Sovietique. Apres dix annes, V. Sarabianov

Movimiento. Comunista Internacional: L'activite de l'IC du V au VI Congres; La Internationale Communiste et la guerre; Le bilan ecrasant des finances du cartel et l'Union National; Les lois militaires de l'imperialisme francais; XV Congres du PC de l'URSS

Literatura: Le ciment, Fedor Galdkov

Tampoco dejaron de sentirse sospechas y dudas respecto de la pertinencia y calidad de alguna traducción hecha en nuestro medio. En 1927, la traducción al español (desde inglés) hecha por el uruguayo Homero Peyrot del texto de Nicolás Bujarin, El materialismo histórico, fue ácidamente referenciada por Marcel Albert (desconocemos datos de este). Albert no sólo trató despectivamente al autor ruso, sino también, las insuficiencias del traductor. El asunto produjo molestia, debiendo el crítico aclarar sus dichos, ver "Bibliografía” y “Una aclaración”, en $L a$ Correspondencia Sudamericana, 28, 31 julio 1927, p. 32, y Ns 30 y 31, septiembre 1927, p.14.

$28 \mathrm{Su}$ existencia fue de una década, 1925-1934.

${ }^{29}$ Duración: 1930-1936. Radicado en Nueva York, el comunismo mexicano bregó constantemente por su control e influencia. En una carta confidencial de 1935, se puede leer: "hay que crear en México una Comisión del Caribe que se ocuparía del estudio de problemas de nuestros países y, con la ayuda a los partidos, con consejos e instrucciones, incluyendo ayuda personal (en algunos casos) de sus miembros... Esa comisión no será una representación oficial de la IC y tampoco tendrá los poderes del Buró del Caribe. Se ocupará, en concreto, con mantener los contactos con los PP.CC. recibiendo de estos informaciones y datos sobre situación en sus países, sus problemas y retos, etc., discutiendo estos problemas con el objeto de ayudar a tiempo a los partidos con indicaciones; organizar la distribución de literatura desde México por varios países (ya que está resuelto fundar 
y Colombia), Ricardo Melgar ha demostrado que ellas, en calidad de órganos principales, correspondieron a la prensa periódica (revistas, boletines), además de una colaboración variada con publicaciones de solidaridad, antiimperialistas y culturales de alcances nacionales como subregionales. Respecto de folletos y libros, la preeminencia estuvo del lado del Buró rioplatense, no sin intermitencias y limitaciones.

Actuando como impresora y distribuidora, fue la Editorial SUDAM el primer intento, relativamente consistente, de gestión editorial de monografías llevado a cabo por el SSA a partir de 1929. Aparte de Buenos Aires y sus alrededores, su actuación buscó proyectarse particularmente entre los países vecinos (Uruguay, Brasil, Paraguay, Bolivia, Perú3 ${ }^{30}$, sin que su influjo haya alcanzado logros significativos. Su origen derivó de la reorganización a que este Secretariado fue sometido a mediados de 1928 por parte del Presidium de la IC ${ }^{31}$. En su primera reunión tras la intervención central, se estipuló que, en asuntos de impresiones, se crearía un Bureau que, además de seguir con la revista La Correspondencia Sudamericana ${ }^{32}$, pondría en circulación un Boletín ${ }^{33}$. De igual manera, se programaría la aparición, en español y portugués, de obras de Marx y Lenin, junto con lo

en México un centro editorial para el Caribe); ayudar a los PP.CC en la enseñanza de sus miembros y formación de sus cuadros. En casos especiales, un miembro de la Comisión puede ir a uno o varios países para estudiar allá la situación y problemas contribuyendo a su resolución".

Confidencial, CARTA DEL DELEGADO DEL PCM H. LABORDE AL SECRETARIADO DE AMÉRICA DEL SUR Y DEL CARIBE DE LA KOMINTERN. Octubre 5, de 1935, en Jeifets y Schelchkov, Op. Cit. p. 1107

30 Perú. CARTA DEL SSAIC A R. MARTÍNEZ DE LA TORRE. Buenos Aires, marzo 29 de 1929.

Compañero R. Martínez de la Torre: A propósito de ediciones, nos es grato comunicarle que teniendo en cuenta la falta de literatura comunista en español, el Komintern ha resuelto crear una editorial sudamericana para publicar las tesis, resoluciones y documentos de la I.C., libros de carácter teórico y, especialmente, las obras más importantes de Marx y de Lenin. En Jeifets y Schelchkov, Op. Cit, p. 1181

31 Consignemos que el desarrollo de esta iniciativa editorial también vista y refrendada en la Primera Conferencia Comunista Latinoamericana realizada en Buenos Aires durante la primera quincena de junio de 1929. Al respecto, el documento de resoluciones de la reunión expuso: “La Conferencia ha comprobado también que el nivel político de todos nuestros Partidos debe ser elevando. La incomprensión de la táctica, y las desviaciones en la aplicación de la misma, son, en parte, el resultado de la incomprensión política de nuestros Partidos. De allí que la Conferencia, al mismo tiempo que daba la consigna de estudiar más en las organizaciones del Partido los problemas nacionales e internacionales y la táctica a seguirse ante los mismos, recomendaba a la Internacional Comunista y al Secretariado Sudamericano, la necesidad de crear escuelas para dar nociones básicas y formar elementos de dirección. La Conferencia acogió con satisfacción la iniciativa de la IC de publicar también sus órganos oficiales en castellano; la creación de una Editorial para la publicación de libros teóricos; el propósito de darle más carácter teórico a la revista del Secretariado Sudamericano, en fin, el esfuerzo que realiza actualmente la IC para contribuir a la elevación el nivel político de los partidos latinoamericanos" "La importancia de la Primera Conferencia Comunista Latino-Americana", en La Correspondencia Sudamericana, 15, 2da época, Buenos Aires, agosto 1929, p. 7

32 Efectivamente continuó su publicación como Segunda Época. Para el detalle de contenidos de sus 27 ediciones (1926-1930), ver Melgar Bao, Op. Cit. A La Correspondencia siguió la Revista Comunista, editada por el SSA en Montevideo. Tuvo en total 7 ediciones, desde septiembre de 1930 hasta octubre de 1932, lo cual habla de las varias interrupciones en su aparición. Ricardo Melgar (p. 106), habla de 6 ediciones, no consignando la séptima, de octubre del 32.

33 Comenzó su aparición en septiembre de 1930 como Boletín del Bureau Sudamericano de la Internacional Comunista. Su periodicidad semanal no siempre se cumplió, tendiendo a aparecer quincenalmente. Hasta finales de 1931, consta la preparación de 23 números. A diferencia de la Revista, este Boletín se propuso abordar pocos temas por edición (en promedio, de 3 a 4) para intensificar los antecedentes. Desconocemos la fecha de su suspensión definitiva. 
más destacado de la folletería de divulgación del marxismo-leninismo. Por último, tomaría en sus manos la salida de los documentos más relevantes de la Internacional ${ }^{34}$.

Según lo revisado hasta ahora, la oferta literaria prevista para SUDAM se cumplió solo en algunos aspectos, siendo predominante la actuación impresora en materiales como informes, discursos, estatutos, manifiestos, resoluciones o actas de congresos emanados de las distintas instancias centrales y sectoriales de la múltiple institucionalidad cominterniana. Un emisor sobresaliente en este ámbito correspondió a las revistas y boletines que, de manera más constante, habían nutrido a las prensas locales de la IC ${ }^{35}$ Lo dicho no obsta para omitir algunos folletos de autores locales como los de José Vidal Mata La verdad sobre Rusia, o de Paulino González Alberdi El movimiento revolucionario latinoamericano, así como tres textos auspiciados por la Confederación Sindical Latino Americana entre 1929-3036. A estos se unieron trabajos de "Kamor" La Internacional Comunista como directora de la lucha por la dictadura proletaria mundial y El movimiento revolucionario en los países coloniales y semicoloniales; Acta de acusación presentada al proceso del Partido Industrial, de N. Krylenko, prefacio de Marcel Cachin, además de algunas reimpresiones de textos que pocos años antes había

34 "La I sesión del Secretariado Sudamericano de la Internacional Comunista", La Correspondencia Sudamericana, 2da época, 1, 1 agosto 1928, p.9 Evidenciando alguna rivalidad con sus colegas del sur, hay indicios que llevan a suponer que los comunistas mexicanos aspiraron a reclamar alguna paternidad o incidencia en las decisiones editoriales que, respecto de la región, había tomado la dirección moscovita de la Comintern. Obsérvese el tenor de la siguiente comunicación: INFORME DE LA DELEGACION DEL PARTIDO COMUNISTA DE MEXICO AL VI CONGRESO DE LA INTERNACIONAL COMUNISTA, 20 de noviembre de 1928: “Por gestiones de la Delegación Mexicana y demás Delegaciones Latino Americanas se creará una Editorial para libros en español en Paris, de la cual serán dependencia o sucursales la Editorial existente ya en Buenos Aires y la que se creará en la Ciudad de México". Además, "Actividades de la delegación mexicana en su viaje a Moscú (...) Paris, reuniones Editorial Partido Francés arregló creación Editorial Español en Paris y conexiones con sucursal en México", en Jeifets y Schelchkov, Op. Cit, pp. 1047 y 1049

No sabemos a qué editorial "ya existente en Buenos Aires" refieren los mexicanos. Tal vez si sea el proyecto de lo que sería SUDAM, asunto que probablemente fue expuesto por los argentinos en el VI Congreso de la IC, de junio de 1928. Recordemos que este evento acordó la creación en Paris de un área editorial para materiales en español, tomando el nombre Ediciones Europa-América. Luego de un primer momento de actividad (1929-30), las disensiones y acusaciones de trotskismo a varios de sus administradores, hacen decaer su impulso. En 1932, recobra bríos por medio de la actuación del funcionario italiano de la IC, Ettore Quaglierini (Pablo Bono Piombo), trasladando el centro de operaciones a España (Barcelona, Madrid). Con suerte dispar, la actuación de EuropaAmérica (rebautizada en España como EDEYA) se mantendrá hasta finales de los años 30. Ahora bien, más allá de los afanes protagónicos de argentinos y mexicanos, lo concreto fue que ambos tuvieron y distribuyeron publicaciones de los sellos europeos citados.

35 Nos referimos a la mencionada revista La Correspondencia Sudamericana; al Boletín del Bureau, a la revista Correspondencia Sudamericana Juvenil, Revista Comunista, o al quincenario El trabajador Latinoamericano, entre otras. Sobre este último título, Melgar Bao entrega un detalle de los sumarios de la revista hasta el número 9, de 15 de enero de 1929. La serie, sin embargo, es mayor, terminando con los números 34-35 de agosto y septiembre de 1930.

36 La Confederación Sindical Latinoamericana (CSLA) -contraparte regional de la Profintern o ISR- fue creada en Montevideo en mayo 1929 y disuelta al crearse la CTAL, en 1938. Como se aprecia, la constitución de la CSLA ocurrió un mes antes de la Primera Conferencia Comunista Latinoamericana, en Buenos Aires. En tanto órgano de la ISR, la CSLA publicó varios folletos, en especial del dirigente máximo de la Internacional Sindical, Solomon Lozovsky. 
publicado el PCA, a saber: Diez días que estremecieron al mundo, de John Reed; y, Páginas Escogidas, obras de Lenin en 4 volúmenes ${ }^{37}$.

En cuanto a publicaciones periódicas en distribución -al parecer, la parte más dinámica del sello- se cuenta la venta directa y suscripción de La correspondencia Internacional; Semanario de información revolucionaria; La Sindical Roja; Cahiers du Bolchevisme (PCF); La Correspondencia Sudamericana; Lo Stato Operario; L'International Communiste; El trabajador latinoamericano ${ }^{38}$

Con el traslado del SSA de Buenos Aires a Montevideo (final de 1930), SUDAM también cambiaría de domicilio a esta última ciudad, haciendo un ajuste en su denominación a Editorial Sud América. No sabemos la fecha exacta de su entrada en funcionamiento ni cuando cesa su actividad. Contamos sólo con una breve relación de sus textos aparecida en la Revista Comunista, de octubre de 193239. Ciertamente que lo más llamativo de tal difusión es que logramos ahora verificar la relación establecida entre Sud América y las casas editoriales comunistas Europa-América y su gestión hispana, EDEYA. Del nutrido catálogo europeo ${ }^{40}$, los representantes del Río de la Plata aparecen ofreciendo los 5 primeros títulos de una más vasta Biblioteca Marxista ${ }^{41}$ : de V.I. Lenin, El Estado y la

37 Es probable que los títulos de folletos y libros de SUDAM sean mayores a los indicados. La información disponible en el momento por parte de Horacio A. López, Op. Cit., nos merece dudas, de modo que evitamos acogerla aquí.

38 La estrategia comercial, en especial para revistas, contempló descuentos por volumen, así como costos de despacho (franqueo) asumidos por el comprador.

39 La publicidad ofrecía: de J. Stalin, La lucha por el leninismo y Análisis críticos de los errores de Trotski. De V. Molotov, Lo que será el 2do Plan Quinquenal y Discurso en la XVIII Conferencia del Partido Comunista Bolchevique de la URSS. De E. Ghitor (Orestes Ghioldi), La bancarrota del anarco-sindicalismo; Hacia un movimiento revolucionario de masas en A. Latina; Problemas de organización. Del SSA: Qué debemos hacer. Folleto elemental; Lo que debes saber trabajador para conquistar tu pan y tu libertad; Importante recopilación de artículos de Lenin sobre la guerra. La oferta se completaba con ediciones en castellano de Internacional Comunista y de La Correspondencia Internacional

40 Para una información ilustrativa de estos sellos y su funcionamiento, ver "Ediciones Europa-América, 19291939", Filosofía en español, web http:/ / www.filosofia.org/ave/001/a438.htm Otros interesantes datos están en Gonzalo Santonja, La República de los libros. El nuevo libro popular de la Segunda República, Anthropos, Barcelona, 1989; Mayte Gómez, El largo viaje. Política y cultura en la evolución del Partido Comunista de España, 1920-1939, Ediciones de la Torre, Madrid, 2005

41 "La Biblioteca Marxista -señalaba el anuncio- es el primer intento serio que se lleva cabo para dar a conocer en lengua castellana las obras fundamentales del marxismo. La BIBLIOTECA MARXISTA publicará 5 o 6 volúmenes anuales de 200 a 300 páginas esmeradamente impresas, traducidos directamente de su idioma original, revisados y corregidos por el Instituto Marx-Engels de Moscú, y acompañados de notas explicativas para facilitar su estudio". Según la referencia de la nota anterior, otros textos considerados en la Biblioteca Marxista, eran:

K. Marx, El trabajo asalariado. Precio, salario y plusvalía.

F. Engels, Del socialismo utópico al socialismo científico.

K. Marx, La Comuna de París.

Stalin, Cuestiones del leninismo.

V. I. Lenin, La revolución proletaria y el renegado Kautsky.

F. Engels, La guerra de los campesinos en Alemania.

Marx y Engels, Antología del materialismo histórico.

Rosa Luxemburg, ¿Reformas o Revolución?

J. Plejanov, El socialismo y la lucha política.

A. Bebel, La mujer y el socialismo.

F. Mehring, Historia de la literatura. 
Revolución; El Imperialismo, etapa superior del capitalismo; El extremismo, enfermedad infantil del comunismo. De J.V. Plejanov, Anarquismo y Socialismo; y de K. Marx y F. Engels, El manifiesto Comunista.

Quedará para otro momento dar cuenta de la proporción y resultados de la presencia en A. Latina de los libros que la Comintern producía en Europa. La proximidad de la guerra general, hacia finales de los años 30, sin olvidar el propio conflicto español de 1936, condicionarían fuertemente este movimiento literario. Lo que al parecer sí contribuyó a suscitar en nuestras tierras, fue un persistente incremento por consultar libros y folletería marxistas, estimulando la actividad de editores conocidos como nuevos, cercanos o no al comunismo. De esta manera, en el transcurso de los años 30 y más aún, con la solidaridad y hasta prestigio que alcanzó la URSS y su sacrificio bélico, la edición marxista, en sus diversas variantes, autorías y temáticas, ganó un cierto espacio social y lectoral más allá de las audiencias militantes. Un par de asertos refuerzan esta evolución y perspectiva. De una parte, el mexicano Sebastián Rivera, recientemente ha expuesto:

El cambio del centro organizador de las publicaciones en castellano desde Francia hacia España a principios de la década de 1930, incrementó fuertemente la cantidad de textos producidos desde las editoriales comunistas. Ediciones Europa América, Ediciones Sociales, Editorial Cenit, entre otras, comenzaron a generar y traducir libros baratos sobre marxismo para el mercado latinoamericano. Y dado que las lógicas de esta producción combinaron el éxito comercial con las necesidades partidistas, en lugar de atrofiar la producción local, significaron un importante impulso para las iniciativas locales, especialmente en América Latina ${ }^{42}$.

En Brasil -cuyos representantes ante la IC siempre se quejaron de un trato secundario y no correspondiente a la envergadura de su clase obrera-, el fenómeno del mayor aliento que la edición comunista habría experimentado con el pasar de los años 30, también se habría dejado ver, con un espectacular pick de 120 títulos editados en 1934, según datos reunidos por Edgard Carone. El intento de rebelión comunista de 1935 y sus funestos resultados, derribaron los esfuerzos con un promedio de 20 ediciones anuales hasta inicios de los 4043. En el anhelo de ser tomados con mayor estima, en 1928 un informe brasileño en Moscú aseguraba que "Os camaradas do Rio Grande do Sul editaram 2.000 exemplares do "A.B.C.", cuja edição já se esgotou. No Rio de Janeiro, o PC editou Agrarismo e industrialismo (Obra de Octavio Brandão, 1926) ${ }^{44}$. Em Pernambuco foram editados vários folhetos de propaganda, entre eles, as Noções do Comunismo de Rappoport" ${ }^{45}$

Del mismo modo como se produjo en las secciones comunistas latinoamericanas de habla española, los empeños editoriales del comunismo carioca -que ya contaban con una

K. Marx, El 18 de Brumario de Luis Bonaparte.

42 Sebastián Rivera Mir, “Los impresos comunistas en el México de inicios de la década de 1930”, Los impresos comunistas en el México de inicios de la década de 1930. Prácticas políticas, represión y clandestinidad Ponencia Segundo Congreso Internacional de la ALIHS, 2017

43 Véase la excelente compilación de Midori y Mollier antes citada

${ }^{44}$ Es considerada la primera tentativa de análisis de la realidad brasileña con categorías marxistas

45 RELATÓRIO À I.C. APRESENTADO PELA DELEGAÇÃO BRASILEIRA POR OCASIÃO DO IV CONGRESSO DA I.S.V. en Jeifets y Schelkov, Op. Cit. p.614 y siguientes 
tradición nada menor ${ }^{46}$ - radicaron su auge en pequeños talleres y unos cuantos editores dispuestos a asumir los riesgos, como, efectivamente, tuvieron que soportar luego de $1935^{47}$.

Em alguns casos -nos expone Rodrigo Patto Sá Motta- há indícios que o partido forneceu os fundos para o início das atividades, mas encarregou algum intelectual ou militante de gerir o negócio; em outras situações eram intelectuais ligados ao partido, ou dissidentes dele (o caso da Unitas, fundada por militantes trotskistas) os responsáveis por abrir e tocar as editoras. De qualquer modo, a linha editorial dessas "casas" seguia os ditames do projeto comunista. Esse breve surto de publicações de esquerda resultou, principalmente, na tradução de clássicos do marxismo e de textos de "literatura proletária" (romance, memórias, poesia), tornando a circulação das idéias e valores comunistas no país mais fácil. As editoras referidas tiveram existência efêmera, em grande medida como resultado da ação policial, que se fez notar de modo mais intenso a partir de 1935. Aquelas que não foram diretamente proibidas de funcionar faliram em decorrência dos prejuízos causados pelo recolhimento dos livros, considerados atentatórios à manutenção da ordem política e social, o que implicou, muita vez, a perda e destruição de milhares de exemplares ${ }^{48}$.

La debacle organizacional y política de la segunda mitad de los 30, importó que el repunte que, al menos en el plano editorial comenzó a vislumbrase en 1942, fuera aprovechado por unas pocas casas de edición de filiación partidaria, sobresaliendo Calvino, abriéndose así una nueva etapa ${ }^{49}$.

Ela pertencia a José Calvino Filho, personagem curioso do nosso universo editorial que, por sua trajetória e atitudes audazes e polêmicas valeria a pena ser mais bem pesquisado. As ligações de Calvino com os comunistas só se tornaram claras em 1945, o que explica sua longevidade como editor, e a façanha de ter sobrevivido no mercado de livros durante os difíceis anos da ditadura. A sobrevivência de sua casa editorial deveu-se também à existência de um catálogo amplo, não restrito a publicações de esquerda. Quando o ambiente político tornou impossível publicar obras de esquerda, Calvino concentrou-se em edições voltadas para medicina e psicologia. Vamos encontrá-lo em 1943, após anos de afastamento da temática política, testando os limites da ditadura e provocando os setores conservadores, ao lançar no mercado títulos simpáticos à União Soviética. Ele enfrentou as críticas provenientes da direita com vigor, defendendo seus livros e convicções em debates públicos travados na grande imprensa. Aliás, como se verá adiante, Calvino Filho publicou os livros dedicados à URSS de maior sucesso de público e vendagem no Brasil

\footnotetext{
46 Marcelo Badaró Mattos, “O Manifesto Comunista no Brasil”, Varia Historia, Belo Horizonte, 22, enero 2000, pp.170-182; José Carlos Ruy, Anotações sobre a história do marxismo no Brasil, en https:// bit.ly/2We64dl

47 Entre las editoriales, se cita a MARENGLEN, Lux, Caramuru, Selma, Alba, Soviet, Adersen, Cultura brasileira, Unitas y Calvino.

48 Rodrigo Patto Sá Motta "A verdadeira pátria dos trabalhadores: a URSS e as edições comunistas", en Márcia Abreu e Nelson Schapochnik (org.) Cultura letrada no Brasil: objetos e práticas, Campinas, Mercado de Letras, 2005, v.1, p. 343-365.

49 Sobre esta, puede consultarse Vinícius Juberte, “José Calvino Filho: A Trajetória de um editor comunista no Brasil (1930-1959)", Revista Amoxtli, 1, segundo semestre 2018, pp. 1-18
} 
Aledaño a esta paulatina expansión del libro político, el hecho también dispuso de otro dato relevante: el mayor asomo en los catálogos y avisos partidarios, de una determina producción propia, surgencia que no sólo tenía que ver con los frecuentes informes y alocuciones dirigenciales, sino, de modo prácticamente inédito, con la publicación de numerosa narrativa (novelas y cuentos) de vertiente social, así como de una ensayística de reflexión histórica, nacional, étnica y continental. Sin duda, se pueden discutir sus alcances y méritos ${ }^{50}$, sin embargo, lo interesante para nosotros fue que, encaminándonos a la década de los 40, el libro comunista regional adquiere visos de diversidad. Aclaremos: no se trató de una diversidad que abarcara a todas las secciones nacionales; tampoco, de modo general, se estuvo dispuesto a cuestionar opciones funcionales y estéticas "realistas" que, desde hacía varios años, se observaban restrictivas y escolásticas aun en el propio mundo comunista. De ahí que, en distintos casos, los resultados de cuño literario fuesen ostensiblemente mediocres, con su insistencia en lo modélico, pedagógico o esópico. Empero, con los aportes narrativos, la edición monográfica dejará de ser puramente política o ideológica, suscitándose un acercamiento, más de hecho que meditado, entre lo partidario y lo creativointelectual ${ }^{51}$.

\section{Conclusiones}

Como se indicó al inicio, creemos haber señalado algunos de los hitos de relevancia respecto de la actuación editorial monográfica que la Internacional Comunista tuvo en nuestra región. Se trata de un primer acercamiento que traza lineamientos y entrega pistas para nuevos trabajos sobre la materia, de manera de ampliar y precisar informaciones e interpretaciones. Abordamos el problema en el convencimiento de que una apertura hacia cuestiones culturales y sus múltiples elementos y relaciones, debería dar algún nuevo brío a los estudios sobre la IC en América Latina. Sin duda que la tarea es vasta y llena de variantes y derivaciones. Por de pronto, seguir avanzando en la construcción de catálogos, la identificación de las organizaciones y personas que se involucraron en su gestión; caracterizar los alcances del rol cumplido por las editoriales comunistas europeas particularmente españolas y francesas-; los modos sobre cómo se acoplaron o no las iniciativas cominternianas con la tradición editorial local; la caracterización de públicos y productos lecturables, etc. son, entre muchos, algunos de los tópicos que habrá que seguir insistiendo. No obstante, lo hecho, todavía esta área de investigaciones tiene entre nosotros una realidad débil, con más incógnitas que claridades, y son diversas las disciplinas y

\footnotetext{
50 Como muy bien acaba de hacerlo Adriana Petra, Op. Cit.

51 Quizá si las versiones mejor logradas de literatura popular proletaria y de ensayo histórico-social entre los medios comunistas de la región, se dio en México, Chile, Costa Rica, Brasil, Argentina. Menciono esto no sin cautela por corresponder a un ámbito amplio y complejo. Ver, Geferson Santana

“O romance proletário Cacau: produção literária de Jorge Amado nos moldes do realismo socialista da URSS", en Revista Amoxtli, 2, primer semestre 2019, y “O realismo socialista e o romance proletário: historiografia e crítica literária (1931-1937), revista Izquierdas, 49, abril, 2020; Lucía Vera, La colección Los Nuevos de la Editorial Claridad. Un análisis desde los criterios materiales y literarios de su composición, Revista Amoxtli, 2, primer semestre 2019. Iván Molina Jiménez, “La producción impresa del Partido Comunista de Costa Rica (1931-1948)”, Iberoamericana, XI, 41, 2011. Sin duda, sobre este mismo punto son imprescindibles los trabajos de A. Petra, R. Melgar, H. Tarcus, R. Pittaluga, D. Spencer, M. Oliva, entre varios más.
} 
enfoques epistemológicos que deberían concurrir en auxilio de nuestro oficio para alcanzar resultados más satisfactorios.

Una inquietud que está presente en nuestro actuar, además de lo dicho, se relaciona con obtener perspectivas analíticas y heurísticas que, en algún sentido, aporten a la necesaria superación de conceptualizaciones e interpretaciones que hasta hoy controlan las explicaciones que se dan frente a asuntos como la bolchevización y la estalinización en las secciones o partidos comunistas de este lado del mundo. Asumo que preguntas similares se han hecho o podrán estar haciéndose para experiencias comunistas de otras latitudes; empero, lo que mueve a nuestra atención no puede escapar de lo acontecido en nuestras tierras.

Desde hace por lo menos 50 años (en el terreno historiográfico), es un lugar común aludir a los términos citados como hechos o acontecimientos negativos, y de efectos constantes y universales. Con ello se sesgó la indagación histórica, tornándose maniquea y, peor aún, la poca historiografía comunista de la región, evitó pronunciarse sobre diversos asuntos que excedían la década de los años 30 movida por un sentimiento de culpa o vergüenza política y académica que perdura hasta hoy. No en vano, sin dejar de mencionar la imposibilidad de acceder a documentos y fuentes de custodia soviética, la propia historia de la Comintern fue silenciada o evitada como muestra de incomodidad y vulnerabilidad. De cierta forma, este eludir constantemente las prácticas que prefiguran la bolchevización y la estalinización, no hizo sino colaborar a la instalación y crecimiento del repudio con que se las asocia.

Sólo en lo que toca al siglo XX, existe una masa infinita de autores y estudios sobre los tópicos del poder, su omnipresencia y sus múltiples expresiones. El punto es que en A. Latina poco o nada de esta producción ha sido vista y tratada por los historiadores locales, comunistas y no comunistas. Ello ha redundado en una completa carencia de recursos para enfrentar relativamente airosos los desafíos de la política y sus operadores prácticos e ideológicos. Con esto queremos decir que el imperio de la política y sus narrativas han subsumido toda complejidad específica y efectivamente histórica. Por ello es que el ejercicio historiográfico comunista o sobre el comunismo, si bien puede arrojar nuevos datos, no ha podido vérselas con las ideas y visiones totémicas, como son las del bolchevismo y estalinismo.

Suponemos que la historia editorial -y otras miradas- pueden escabullir el imperialismo de la narrativa política al uso. No es que neguemos la bolchevización y la estalinización. Tales manifestaciones fueron y son todavía parte importante de la cultura política comunista (aunque no sólo comunista). Lo que sostenemos es que estas otras formas de vadearlas no sólo podrían descomprimir la presión del tratamiento de la historia política conocida, sino, a la par, aportar a un ajuste heurístico más pertinente a las "realidades" del bolchevismo y el estalinismo en A. Latina. Es conveniente muchas veces asumir los procedimientos de los tipos ideales; no obstante, hacer de ellos la canónica de toda forma y contenido resulta muy perjudicial y nos estanca. En síntesis, la intención de nuestra historia del libro y folleto comunista en tiempos de la Comintern es una forma de acercarnos a tal poder y estructuras, no para reiterar lo de siempre, sino para, de un lado, resituar tal objeto en nuestras posibilidades de conocimiento concreto, y de otro, dejar de sentirnos inermes delante de hechos que, por fuerza, seguirán acompañándonos. 


\section{Referencias bibliográficas generales}

Acevedo, Nicolás, Un fantasma recorre el campo. Comunismo y politización campesina en Chile (1935-1948), Ed. América en Movimiento, 2017

Angenot, Marc, Interdiscursividades. De hegemonías y disidencias, Editorial Universidad nacional de Córdoba, 2010

Badaró Mattos, Marcelo, “O Manifesto Comunista no Brasil”, Varia Historia, Belo Horizonte, 22, enero 2000, pp.170-182

Bouju, Marie-Cécile, Lire en communiste. Les maisons d'édition du Parti Communiste franÇais, 1920-1968, Presses Universitaires de Rennes, 2010

Camarero, Hernán, A la conquista de la clase obrera. Los comunistas y el mundo del trabajo en la Argentina, 1920-1935, Siglo XXI, Buenos Aires, 2007

Clementi, Hebe, Lautaro. Historia de una editorial, Leviatán, B. Aires, 2004

Concheiro, Elvira, "Repensar a los comunistas en América Latina, revista Izquierdas, 7, año 3 (2010), pp. 1-19

Chartier, Roger, “Textos, impresão, leituras”, en Lynn Hunt, A Nova Historia Cultural, Martins Fontes, São Paulo, 2001

Darnton, Robert, "Historia da leitura", en Peter Burke, organizador, A Escrita da historia. Novas perspectivas, Editora Unesp, São Paulo, 1992

Ducange, Jean-Numa, Julien Hage, Jean-Yves Mollier (edits.) Le Parti Communiste fran Çais et le libre. Écrire et diffuser le politique en France au XXe siècle (1920-1992), Editions Universitaires de Dijon, 2014

Groppo, Bruno, "Historiens et historiographie du communisme en Italie", Revista Izquierdas, 15, abril 2013, pp. 170-192, en https://bit.ly/2KvmOIt ;

Herrera, Patricio y Santiago Aránguiz, edits., El Comunismo en América Latina. Experiencias militantes, intelectuales y transnacionales (1917-1955), Universidad de Valparaíso, Valparaíso, 2017

Jeifets, Lazar y Víctor Jeifets, América Latina en la Internacional Comunista. 1919-1943. Diccionario Biográfico, Ariadna Ediciones, Santiago, 2015, en https://bit.ly/2WY4Gs2

Jeifets, Víctor y Andrey Schelchkov, América Latina en los archivos de la Comintern en Moscú, Academia de Ciencias de Rusia-Instituto de Historia Universal, Ariadna ediciones, Santiago, 2019

Juberte, Vinícius, “José Calvino Filho: A Trajetória de um editor comunista no Brasil (1930-1959)", Revista Amoxtli, 1, segundo semestre 2018, pp. 1-18

Leibner, Gerardo, Camaradas y compañeros. Una historia política y social de los comunistas del Uruguay, TRILCE, Montevideo, 2011

López, Horacio, Las editoriales rojas: de La Internacional a Cartago, Ediciones Luxemburg, Buenos Aires, 2018

Loyola, Manuel, “A associação de amigos da União Soviética no Chile 1927-1943", en Estudos Iberoamericanos, 1, 42, 2016, DOI http://dx.doi.org/10.15448/1980$\underline{864 X .2016 .1 .21647}$

Loyola, Manuel, "Lecturas rojas: libros y folletos comunistas en Chile, 1920-1926", en Hernán Camarero y Manuel Loyola, Editores, Política y cultura en los sectores populares y de 
las izquierdas latinoamericanas en el siglo XX, Ariadna Ediciones, Santiago, 2016

McKenzie, DF, Bibliografía y sociología de los textos, Akal, Madrid, 2005

Melgar Bao, Ricardo, La prensa militante en América latina y la Internacional Comunista, Instituto Nacional de Antropología e Historia, México DF, 2015

Midori Deaecto, Marisa y Jean-Yves Mollier, Edicão e revolucão. Leituras comunistas no Brasil e na FranÇa, Ateliê Editorial, Editora UFMG, São Paulo, 2013

Molina Jiménez, Iván, "La producción impresa del Partido Comunista de Costa Rica (1931-1948)", Iberoamericana, XI, 41, 2011.

Neumann, Matthias, La Liga de las Juventudes Comunistas y la transformación de la Unión Soviética (1917-1932), Ariadna Ediciones, Santiago, 2019

Patto Sá Motta, Rodrigo, "A verdadeira pátria dos trabalhadores: a URSS e as edições comunistas", en Márcia Abreu e Nelson Schapochnik (org.) Cultura letrada no Brasil: objetos e práticas, Campinas, Mercado de Letras, 2005, v.1, p. 343-365.

Petra, Adriana, Intelectuales y cultura comunista. Itinerarios, problemas y debates en la Argentina de postguerra, FCE, B. Aires, 2017

Porrini, Rodolfo, Montevideo, ciudad obrera. El 'tiempo libre' desde las izquierdas (1920-1950), CSIC, Universidad de La República, Montevideo, 2019

Prashad, Vijay (editor) The East was read. Socialist Culture in the Third World, LeftWords Books, New Delhi, 2019

Rupprecht, Tobias Soviet Internationalism after Stalin. Interaction and Exchange between the USSR and Latin America during de Cold War, Cambridge University Press, UK, 2015

Santana, Geferson, "O romance proletário Cacau: produção literária de Jorge Amado nos moldes do realismo socialista da URSS", en Revista Amoxtli, 2, primer semestre 2019,

Santana, Geferson, "O realismo socialista e o romance proletário: historiografia e crítica literária (1931-1937), revista Izquierdas, 49, abril, 2020 (adelanto de edición)

Silva, Marisa, Aquellos comunistas (1955-1973), Taurus, Montevideo, 2009

Ruy, José Carlos, Anotações sobre a história do marxismo no Brasil, en https://bit.ly/2We64dl

Ulianova, OLga y Alfredo Riquelme, edits., Chile en los archivos soviéticos, 1922-1991, 3 volúmenes, DIBAM-Centro Barros Arana, Santiago, 2005-2017

Vera, Lucía, "La colección Los Nuevos de la Editorial Claridad. Un análisis desde los criterios materiales y literarios de su composición", Revista Amoxtli, 2, primer semestre 2019 